\title{
Psoriasin: A novel marker linked obesity with psoriasis
}

\author{
Ragaa H.M. Salama ${ }^{\mathrm{a}, *}$, Hani A. Al-Shobaili ${ }^{\mathrm{b}}$, Ahmad A. Al Robaee ${ }^{\mathrm{b}}$ and Abdullateef A. Alzolibani ${ }^{\mathrm{b}}$ \\ ${ }^{a}$ Department of Medical Biochemistry, College of Medicine, Qassim University, Qassim, KSA \\ ${ }^{\mathrm{b}}$ Department of Dermatology, College of Medicine, Qassim University, Qassim, KSA
}

\begin{abstract}
To evaluate the role of psoriasin, koebnerisin, interleukn (IL)-12 and IL-23 in the pathogenesis of psoriasis and their relations to Psoriasis Area Severity Index (PASI) and obesity. Thirty patients had chronic plaque psoriasis and 30 healthy subjects matched in age and sex were enrolled in this study. Serum from all subjects were used for determination of psoriasin, koebnerisin, IL-12 and IL-23 by ELISA kits. IL-23 and psoriasin were significantly higher in skin psoriasis compared to controls and psoriatic arthritis (PsA). There was a correlation between psoriasin and both PASI and obesity. On the other hand, IL-12 was significantly increased in PsA compared to skin psoriasis $(p=0.000)$ and controls. Its sensitivity and specificity were $87 \%, 93 \%$; respectively. To our knowledge, psoriasin is the first biomarker confirm the link between obesity and psoriasis. The risk of developing psoriasis is directly related to higher BMI.
\end{abstract}

Keywords: Psoriasis, psoriasin, kobneriasin, IL-12, IL-23, obesity

\section{Introduction}

The percent of psoriasis in the eastern of Saudi Arabia is 5.3\% [1]. Psoriasin (S100A7) and koebnerisin (S100A15) were first identified in inflamed psoriatic skin. They are of major interest because of their putative functional roles in innate immunity, epidermal cell maturation, and epithelial tumorigenesis [2]. They have evolved by gene duplications within the epidermal differentiation complex (chromosome 1q21) and form a novel S100 subfamily in human. Despite the highest homology, psoriasin and koebnerisin are distinct in tissue distribution, regulation, and function. They act differently as antimicrobial peptides and promote inflammation, cell migration and chemoattractants [3, 4].

*Corresponding author: Ragaa H.M. Salama, Medical Biochemistry, Kingdom of Saudi Arabia, Qassim, Qassim University, Collage of Medicine, P.O. 6655, Buraidah: 51452, Female section. Permanent address: Medical Biochemistry Department, Faculty of Medicine, Assuit University, Assiut, Egypt. Tel: +966 3800050 ext-6043; Fax: +966 3802082; E-mail: ragaa_2002@yahoo.com.
Different cytokines play a part in sustaining the two main characteristics of a psoriatic lesion; keratinocyte hyperproliferation and inflammation. IL-23 is a member of the IL-12 family of cytokines with proinflammatory properties. IL-23 shares the same p40 subunit with IL-12. The anti-p40 monoclonal antibody neutralized the activities of both IL-12 and IL23. These findings point to IL-23, but not IL-12, as the necessary mediator of organ-specific autoimmune diseases [5]. Although IL-23 and IL-12 share structural homologies, they have very distinct biological activities. IL-23 specifically stimulates memory $\mathrm{CD}^{+}$ $\mathrm{T}$ cells, whereas IL-12 is a potent stimulant for naive $\mathrm{CD}^{+} \mathrm{T}$ cells [5]. IL-23 induces strong proliferation of mouse memory $\mathrm{T}$ cells, a unique activity of IL-23 as IL-12 has no effect on this cell population. Human IL-12 and IL-23 stimulate IFN-gamma production and proliferation in blast $\mathrm{T}$ cells. P19 protein engages IL-12p40 to form a cytokine, IL-23, with biological activities similar as well as distinct from IL-12 [5]. Ustekinumab binds to the $\mathrm{p} 40$ subunit common to IL12 and IL-23 and prevents their actions. Ustekinumab is approved for treatment of moderate-to-severe plaque psoriasis and psoriatic arthritis [6]. 
Table 1

Demographic data of all psoriatic patients according to Psoriasis area severity index

\begin{tabular}{|c|c|c|c|c|}
\hline & \multicolumn{3}{|c|}{ Psoriasis Area Severity Index (PASI) } & \multirow[b]{2}{*}{$\mathrm{P}$} \\
\hline & $\begin{array}{c}\text { mild }(0-3) \\
(n=12) \\
\end{array}$ & $\begin{array}{l}\text { moderate }(>3-15) \\
\text { moderate }(n=11)\end{array}$ & $\begin{array}{l}\text { severe }(>15) \\
\text { sever }(n=7) \\
\end{array}$ & \\
\hline \multicolumn{5}{|l|}{ Sex } \\
\hline Male (11) & 5 & 6 & 0 & $0.05^{*}$ \\
\hline Female (19) & 7 & 5 & 7 & \\
\hline \multicolumn{5}{|l|}{ Duration of illness } \\
\hline$>10$ years $(16)$ & 12 & 3 & 1 & $0.000^{*}$ \\
\hline $10-20$ years $(9)$ & 0 & 4 & 5 & \\
\hline$<20$ years $(5)$ & 0 & 4 & 1 & \\
\hline \multicolumn{5}{|l|}{ Type of psoriasis } \\
\hline Skin psoriasis (22) & 9 & 7 & 6 & NS \\
\hline Psoriatic arthritis (8) & 3 & 4 & 1 & \\
\hline \multicolumn{5}{|l|}{ Respond to treatment } \\
\hline No response (6) & 1 & 3 & 2 & NS \\
\hline Mild respond (17) & 8 & 6 & 3 & \\
\hline Moderate (4) & 2 & 0 & 2 & \\
\hline Excellent (3) & 1 & 2 & 0 & \\
\hline \multicolumn{5}{|l|}{ Obesity } \\
\hline Underweight (1) & 1 & 0 & 0 & $0.03^{*}$ \\
\hline Normal (7) & 5 & 1 & 1 & \\
\hline Overweight (9) & 5 & 4 & 0 & \\
\hline Obese (13) & 1 & 6 & 6 & \\
\hline \multicolumn{5}{|l|}{ Family history } \\
\hline Family history of psoriasis (13) & 6 & 7 & 0 & $0.02^{*}$ \\
\hline No family history of psoriasis (17) & 6 & 4 & 7 & \\
\hline \multicolumn{5}{|l|}{ Smoking } \\
\hline Smoker (5) & 1 & 2 & 2 & NS \\
\hline Non-smoker (25) & 11 & 9 & 5 & \\
\hline \multicolumn{5}{|l|}{ Type of treatment } \\
\hline Local (18) & 12 & 2 & 4 & $0.002^{*}$ \\
\hline Systemic (2) & 0 & 2 & 0 & \\
\hline Local + systemic $(10)$ & 0 & 7 & 3 & \\
\hline
\end{tabular}

Chi-square used to compare between qualitative parameters. $P \leqslant 0.05$ is significant. ${ }^{*}$ is significant, NS is non-significant.

Psoriasis is an inflammatory skin disease often associated with obesity. Several studies found a link of psoriasis with obesity [7]. Both overall and central obesity have been associated with the risk of psoriasis in a prospective study. The study provided evidence linking obesity with the risk of incident PsA among US women [8]. Patients with moderate-to-severe psoriasis have a significantly increased risk of cardiovascular disease and cardiovascular risk factors such as obesity, diabetes mellitus, the metabolic syndrome and smoking compared to the general population. Also, there is a potential excess of cardiovascular events with the newer generation of anti-interleukin-12p40 antibodies used in psoriasis therapies [9]. Psoriatic patients with a body mass index of 27 or more are likely to have vitamin $\mathrm{D}$ insufficiency [10]. Obesity may play an additional factor in sever psoriasis that need specific management.

Data on the association between obesity and skin psoriatic or PsA have been sparse. Hence, the aim of this study is to evaluate the role of psoriasin, koebnerisin, IL-12 and IL-23 in the pathogenesis of skin psori- asis and psoriatic arthritis . Also, the relation between PASI, obesity and demographic data of the patients.

\section{Patients and methods}

This is a case control hospital based study. The study was approved by the Regional Research Ethics Committee, Qassim Province, Ministry of Health, KSA. Written informed consent was obtained from each participant after an information sheet was provided. The study included 30 patients diagnosed as chronic plaque psoriasis and 30 healthy controls matched in age and sex. They were subjected to full history taking, routine laboratory investigations, ESR and uric acid were determined. Body mass index (BMI) and Psoriasis Area Severity Index (PASI), presence of arthritis were recorded. Patients with autoimmune disease like rheumatoid or arthritic lesion like gout were excluded. PASI is the most widely used measurement tool for psoriasis [11]. The patients divided into 3 groups accord- 
Table 2

The relation between body mass index and demographic data of cases of psoriasis

\begin{tabular}{|c|c|c|c|c|c|c|}
\hline & & \multicolumn{4}{|c|}{ Body Mass Index (BMI) } & \multirow[b]{2}{*}{$\mathrm{P}$} \\
\hline & & $\begin{array}{l}\text { Underweight } \\
(16.0-18.5)\end{array}$ & $\begin{array}{c}\text { Normal } \\
(18.5-25)\end{array}$ & $\begin{array}{c}\text { Overweight } \\
(25-30)\end{array}$ & $\begin{array}{c}\text { Obesity } \\
<30\end{array}$ & \\
\hline Duration of illness & $\begin{array}{l}>10 \text { years }(n=16) \\
10-20 \text { years }(n=9) \\
<20 \text { years }(n=5)\end{array}$ & $\begin{array}{l}1 \\
0 \\
0\end{array}$ & $\begin{array}{l}6 \\
1 \\
0\end{array}$ & $\begin{array}{l}5 \\
0 \\
4\end{array}$ & $\begin{array}{l}4 \\
8 \\
1\end{array}$ & $0.009^{*}$ \\
\hline Psoriasis severity index & $\begin{array}{l}\operatorname{Mild}(0-3)(n=12) \\
\text { Moderate }(>3-15)(n=11) \\
\text { Severe }(>15)(n=7)\end{array}$ & $\begin{array}{l}1 \\
0 \\
0\end{array}$ & $\begin{array}{l}5 \\
1 \\
1\end{array}$ & $\begin{array}{l}5 \\
4 \\
0\end{array}$ & $\begin{array}{l}1 \\
6 \\
6\end{array}$ & $0.03^{*}$ \\
\hline Type of psoriasis & $\begin{array}{l}\text { Skin psoriasis }(n=22) \\
\text { Psoriatic arthritis }(n=8)\end{array}$ & $\begin{array}{l}1 \\
0\end{array}$ & $\begin{array}{l}5 \\
2\end{array}$ & $\begin{array}{l}7 \\
2\end{array}$ & $\begin{array}{l}9 \\
4\end{array}$ & NS \\
\hline Smoking & $\begin{array}{l}\text { Smoking }(n=5) \\
\text { Nonsmoking }(n=25)\end{array}$ & $\begin{array}{l}0 \\
1\end{array}$ & $\begin{array}{l}0 \\
7\end{array}$ & $\begin{array}{l}0 \\
9\end{array}$ & $\begin{array}{l}5 \\
8\end{array}$ & $0.04^{*}$ \\
\hline Sex & $\begin{array}{l}\text { Male }(n=11) \\
\text { Female }(n=19)\end{array}$ & $\begin{array}{l}0 \\
1\end{array}$ & $\begin{array}{l}0 \\
7\end{array}$ & $\begin{array}{l}6 \\
3\end{array}$ & $\begin{array}{l}5 \\
8\end{array}$ & $0.04^{*}$ \\
\hline Respond to treatment & $\begin{array}{l}\text { No respond }(n=6) \\
\text { Mild respond }(n=17) \\
\text { Moderate }(n=4) \\
\text { Excellent }(n=3)\end{array}$ & $\begin{array}{l}0 \\
1 \\
0 \\
0\end{array}$ & $\begin{array}{l}2 \\
3 \\
2 \\
0\end{array}$ & $\begin{array}{l}0 \\
8 \\
0 \\
1\end{array}$ & $\begin{array}{l}4 \\
5 \\
2 \\
2\end{array}$ & NS \\
\hline Type of treatment & $\begin{array}{l}\text { Local }(n=18) \\
\text { Systemic }(n=2) \\
\text { Local }+ \text { systemic }(n=10)\end{array}$ & $\begin{array}{l}1 \\
0 \\
0\end{array}$ & $\begin{array}{l}6 \\
0 \\
1\end{array}$ & $\begin{array}{l}7 \\
0 \\
2\end{array}$ & $\begin{array}{l}4 \\
2 \\
7\end{array}$ & NS \\
\hline Family history & $\begin{array}{l}\text { Family history }(n=13) \\
\text { No family history }(n=17)\end{array}$ & $\begin{array}{l}0 \\
1\end{array}$ & $\begin{array}{l}3 \\
4\end{array}$ & $\begin{array}{l}6 \\
3\end{array}$ & $\begin{array}{l}4 \\
9\end{array}$ & NS \\
\hline
\end{tabular}

Chi-square used to compare between qualitative parameters. $P \leqslant 0.05$ is significant. ${ }^{*}$ is significant, NS is non-significant.

Table 3

The biochemical markers of skin psoriatic and psoriatic arthritis patients

\begin{tabular}{lllll}
\hline Biomarkers & Control $(n=30)$ & Skin psoriasis $(n=22)$ & Psoriatic arthritis $(n=8)$ & Total cases of psoriasis $(n=30)$ \\
\hline Interlukin-12 $(\mathrm{pg} / \mathrm{ml})$ & $24.9 \pm 5.18$ & $41.8 \pm 12.7$ & $296.5 \pm 76.9$ & $109.5 \pm 29.8$ \\
$\quad$ P value & & NS* & $P=0.000^{*}$ & $=0.007^{*}$ \\
AUC & & 0.574 & 0.921 & 0.763 \\
Interlukin-23 $(\mathrm{pg} / \mathrm{ml})$ & \multirow{2}{*}{$123.86 \pm 4.60$} & $204.78 \pm 24.24$ & $136.56 \pm 15.34$ & $186.59 \pm 18.93$ \\
P value & & $=0.000^{*}$ & $=0.02 \#$ & $=0.002^{*}$ \\
AUC & & 0.767 & 0.413 & 0.708 \\
Psoriasin $(\mathrm{ng} / \mathrm{ml})$ & \multirow{4}{*}{ $\pm .41 \pm 0.26$} & $69.71 \pm 32.34$ & $4.75 \pm 0.98$ & $52.39 \pm 24.16$ \\
P value & & $=0.01^{*}$ & $P=0.01^{\#}$ & $0.05^{*}$ \\
AUC & & 0.725 & 0.416 & 0.67 \\
Kobneriasin $(\mathrm{ng} / \mathrm{ml})$ & \multirow{2}{*}{$17.25 \pm 1.58$} & $35.67 \pm 8.03$ & $26.35 \pm 14.52$ & $33.19 \pm 6.96$ \\
P value & & $=0.02^{*}$ & NS\# & $0.02^{*}$ \\
AUC & & 0.63 & 0.365 & 0.559 \\
\hline
\end{tabular}

${ }^{*}$ Compared to control; \#compared to skin psoriasis only. ANOVA test used to compare between groups. AUC: area under the curve of receiver operating characteristic (ROC) curves. NS: non-significant. T-test used to compare between control and total cases of psoriasis.

ing to PASI, mild ( $>3$ ), moderate (3-15) and severe $(<15)$. Five $\mathrm{ml}$ blood was collected from each patient and control, centrifuged and serum kept at $-80^{\circ} \mathrm{C}$ for biochemical analysis. CircuLex's S100A7/Psoriasin ELISA Kit (Cat\# CY-8073, Japan) was used to estimate psoriasin protein by the quantitative sandwich enzyme immunoassay technique. A polyclonal antibody specific for human S100A7/Psoriasin has been pre-coated onto a microplate. Psoriasin kit could detect psoriasin level from $90.00 \mathrm{ng} / \mathrm{ml}$ to $0.12 \mathrm{ng} / \mathrm{ml}$. Kobneriasin measured by Human S100 calcium binding protein A15
(S100A15) ELISA kit WKEA MED Supplies, USA, code \# WH-1699. Koebnerisin assay could detect level ranges from $4 \mathrm{ng} / \mathrm{ml}$ to $100 \mathrm{ng} / \mathrm{ml}$. IL-12 measured by Human IL-12(P70) RayBio ${ }^{\circledR}$, ELISA Kit (Cat\#: ELHIL12P70-001). IL-12 is a heterodimeric $70 \mathrm{kDa}$ glycoprotein (IL-12-p70) composed of p35 and p40 subunits. We used here IL-12(p70) not (p40), the whole protein not the subunit IL-12(p40). Human IL-23 ELISA Kit, Glory Science USA -CK-E10077, was used to measure IL-23. 


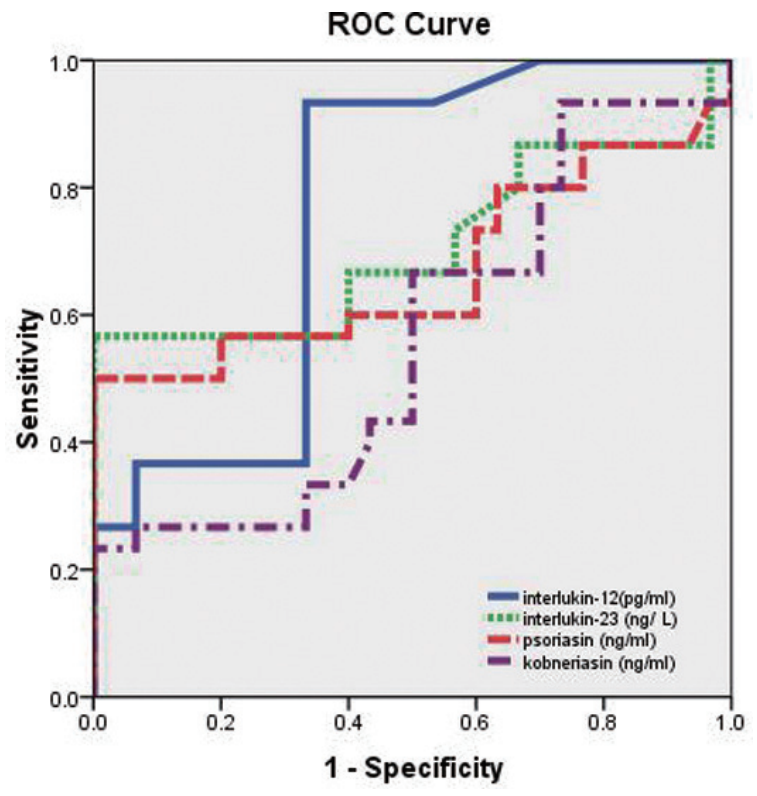

Fig. 1. ROC curves of all cases of psoriasis $(n=30)$ with area under the curve for interlukin- $12(\mathrm{p} 70)=0.76$; interlkin- $23=0.7$; psoriasin $=0.67$; kobneriasin $=0.56$. (Colours are visible in the online version of the article; http://dx.doi.org/10.3233/DMA-120945)

\subsection{Statistical analysis}

Data were analyzed using SPSS version 16. Values were expressed as mean \pm SEM. Results considered statistically significant at $p \leqslant 0.05$. Difference between values assessed by t- test. One-way analysis of variance (ANOVA) test followed by post hoc test (LSD) used to compare between different types of patients. Person's correlation coefficient was calculated to assess the relation between biomarkers and PASI, response to treatment. Receiver operating characteristic (ROC) curves were done and area under the curve (AUC) was used to compare between markers. Sensitivity and specificity of different markers were determined by choosing from the data result of ROC and the best calculated point achieving the highest sum of sensitivity and specificity was used as cut off value. Chi- square was used to compare between qualitative parameters.

\section{Results}

Thirty patients proved to be psoriatic were included in the study. The age of patients ranged from 16 to 56 years, 11 are males and 19 are females. Their BMI ranged from 17.5 to 41.5 . The age of the control subjects ranged from 16 to 60 years, 10 males and 20 fe-

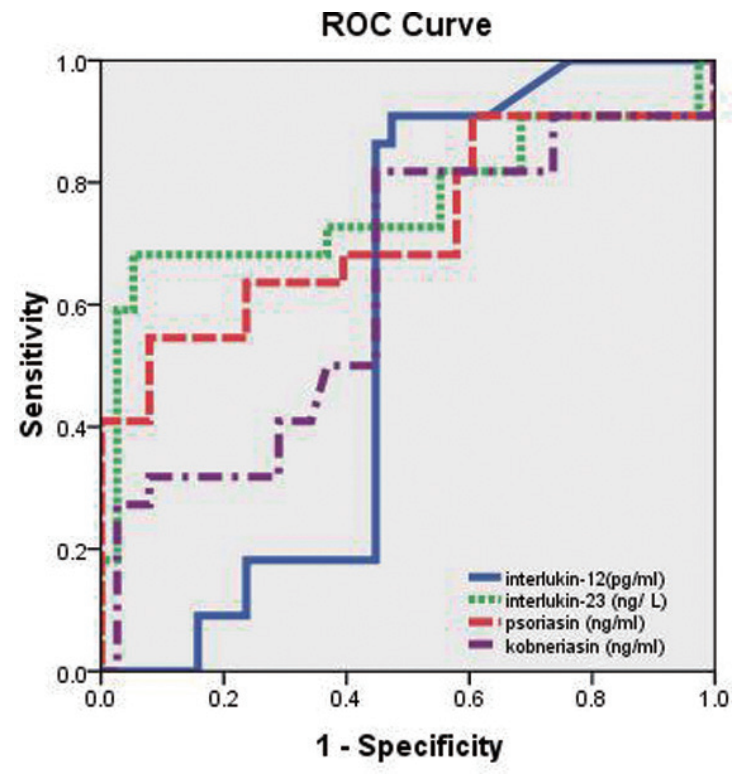

Fig. 2. ROC curves shows cases of skin psoriasis without arthritis $(n=22)$ with area under the curve for interlukin- $12(\mathrm{p} 70)=$ 0.57 ; interlkin-23 $=0.76$; psoriasin $=0.72$; kobneriasin $=0.63$. (Colours are visible in the online version of the article; http://dx.doi. org/10.3233/DMA-120945)

males and their BMI range from 16 to 42.5. Eight out of the thirty patients were fulfilling the CASPAR criteria for psoriatic arthritis (PsA) [12]. The disease duration was from one to 28 years (mean is $10.87 \pm 1.7$ years). The ESR 1st hour was within normal range in all patients with a mean of $14.05 \pm 2.42 \mathrm{mmHg} / \mathrm{lst}$ hour. Routine investigations were all normal. The rheumatoid factor was negative in all cases and the serum uric acid was within normal value. There was no significant correlation between the studied markers level and any of the routine laboratory parameters. According to PASI the patients were 12 mild, 11 moderate and 7 severe. The relation between PASI and demographic data of the patients were demonstrated in Table 1. There was significant increase in non-responders to treatment in females than males ( $p=0.03$ ) by Chi-square. Five out of 6 psoriatic patients that didn't not respond to treatment had no family history of psoriasis $(p=0.000)$ by Chi- square, that indicated the possibility of the presence of another factor most probably obesity. No correlation between PASI and PsA was detected. Table 2 shows the relation between BMI and demographic data of all cases of psoriasis. Psoriasin, koebnerisin, IL-12 and IL-23 were significantly increased in all cases of psoriasis than controls but only IL-12 that was significantly increased in PsA compared to skin psoriasis and controls (Table 3). 


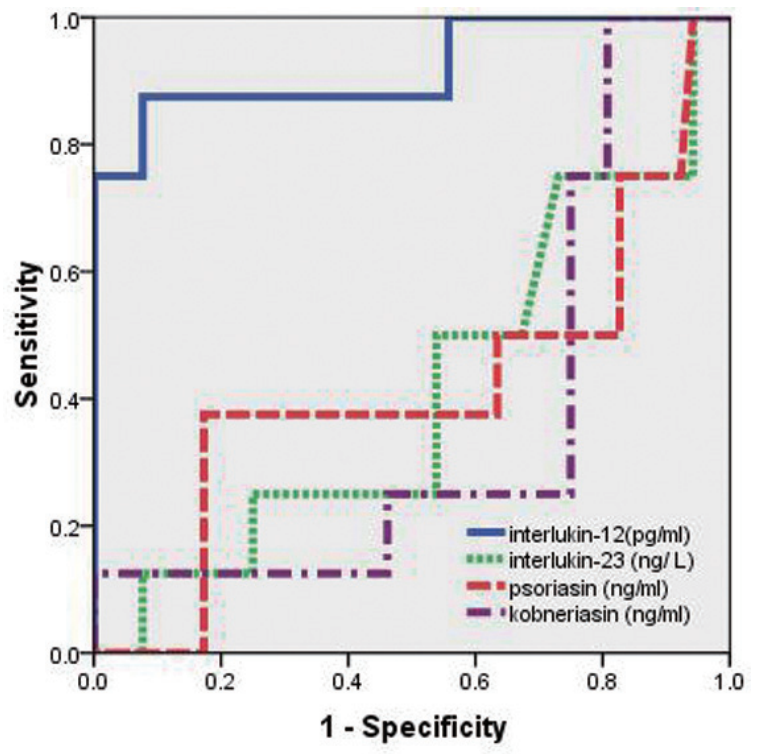

Fig. 3. ROC curves shows cases of psoriatic arthritis $(n=8)$ with area under the curve for interlukin-12 $(\mathrm{p} 70)=0.92$; interlkin-23 $=$ 0.4 , psoriasin $=0.4$; kobneriasin $=0.3$. (Colours are visible in the online version of the article; http://dx.doi.org/10.3233/DMA-120945)

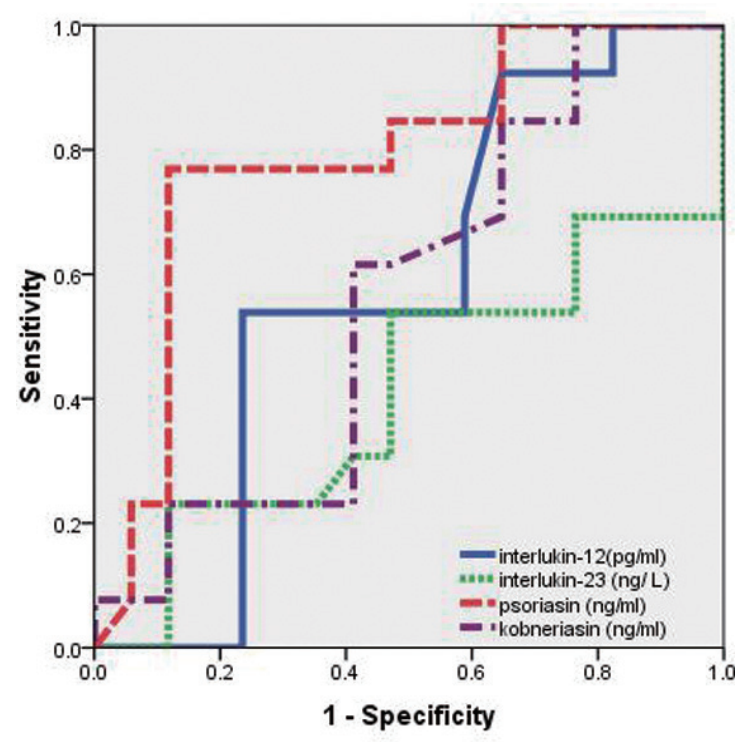

Fig. 4. ROC curves shows psoriatic cases with body mass index $<30,(n=13)$ with area under the curve for interlukin-12 (p70) $=0.57$; interlkin-23 $=0.4$, psoriasin $=0.79$; kobneriasin $=0.56$. (Colours are visible in the online version of the article; http://dx. doi.org/10.3233/DMA-120945)

ROC curves of all cases of psoriasis $(n=30)$ showed that IL-12 had the best area under the curve $(=0.76)$ as in Fig. 1. Cases of skin psoriasis $(n=22)$ shows IL-23 and psoriasin have AUC $=0.76$ and 0.72 , as in
Fig. 2. Psoriatic arthritis cases $(n=8)$ shows IL-12 has $\mathrm{AUC}=0.92$ as in Fig. 3. IL-23 and psoriasin had sensitivity and specificity in skin psoriasis at cut-off 129.35 and $5.18 \mathrm{ng} / \mathrm{ml}$ (73\%, 64\% and 68\%, 61\%; respectively). Whereas, IL-12 had the highest sensitivity and specificity in PsA at cut-off $64.2 \mathrm{pg} / \mathrm{ml}(87 \%$, 93\%; respectively). Figure 4 showed that psoriasin has the largest area under the curve $=0.79$ in cases of BMI $<30,(n=13)$. The total cases of psoriasis showed a correlation between PASI and both psoriasin $(r=0.4 ; P=0.02)$ and BMI $(r=0.58, P=0.001)$. This study demonstrated that the risk of development of psoriasis was directly related to BMI more than 30 ( $r=0.7, P=0.007)$. There is a correlation between IL-23 and kobneriasin $(r=0.3 ; P=0.006)$. Also, there was a correlation between IL-12 and the response to treatment ( $r=0.4 ; P=0.03$ ). By using regression analysis, IL-12 was a good predictor of psoriasis $(P=$ 0.000).

\section{Discussion}

Psoriasis is a common complex genetic disease characterized by hyperplasia and inflammation in the skin. However, the relative contributions of epidermal cells and the immune system to disease pathogenesis remain unclear. Linkage studies have defined a psoriasis susceptibility locus (PSORS4) on 1q21, the epidermal differentiation complex, which includes genes for small calcium-binding proteins (S100) [13]. This is in agreement with this study as psoriasin (S100A7) and koebnerisin (S100A15), were significantly increased in all cases of psoriasis and skin psoriasis compared to controls. There was a correlation between psoriasin and both PASI and BMI. The correlation increased when BMI was more than 30 . This could be explained by the constitutive expression of elevated concentrations of psoriasin and koebnerisin in the epidermis of psoriatic skin. Mice expressing elevated amounts of doxycycline-regulated mS100a7a15 in skin keratinocytes were genetically modified. These mice had exaggerated inflammatory response when challenged by exogenous stimuli such as abrasion (Koebner phenomenon), potentiated inflammation by acting directly as a chemoattractant for leukocytes [13]. Differential Toll-like receptor (TLR4/2) genes expression on psoriatic peripheral blood mononuclear cells were correlated with regulatory proinflammatory cytokines and damage-associated molecule (S100A9) that emphasize innate immune response role in psoriasis [14]. 
Thus, targeting the S100-amplification loop could be a beneficial anti-inflammatory approach in skin psoriasis. In agreement with our results was that Gambichler et al. [15], as the psoriasin level in psoriatic patients was significantly higher than control group (79.4 \pm $32.7 \mathrm{ng} / \mathrm{ml} ; 3.1 \pm 0.7 \mathrm{ng} / \mathrm{ml}, P=0.0001)$. However, when these psoriatic patients received fumaric acid esters therapy, the level was decreased but this may be due to the effect of treatment [15]. IL-23 has the ability to enhance the expansion of T helper type 17 (Th17) cells indicating the responsibility for many of the inflammatory autoimmune responses [16]. In this study, IL-12 and IL-23 were significantly increased in all cases of psoriasis than controls. On the other hand, IL-23 decreased in psoriatic arthritis, whereas IL-12 increased compared to skin psoriasis and controls. However, there was no correlation between PSAI and IL-23 or IL-12 in this study. This is in disagreement with El Hadidi et al. 2008 as they found that IL-23 was over expressed in skin and serum of patients with psoriasis and psoriatic arthritis and its level was correlated with disease severity [17]. IL-12 in PsA had the highest sensitivity and specificity among the studied markers. IL-12 is produced mainly by macrophages and dendritic cells, and induced activation of natural killer cells, production of interferon-gamma (IFN- $\gamma$ ) and differentiation of naive T cells to Th1 cells [18]. In this study, IL-12 was the only marker that increased significantly in psoriatic arthritis and had the highest sensitivity, specificity and AUC of ROC curves in PsA. Contrary, other markers decreased in psoriatic arthritis.

The chronic inflammation and hyperhomocysteinemia found in psoriatic patients may explain the association with atheroma plaque and metabolic syndrome [19]. In a cohort study, obese patients were more likely to have severe psoriasis, patients with severe psoriasis were frequently obese. Importantly, the pathophysiology of both psoriasis and obesity showed many shared cytokines that are known to contribute to features of the metabolic syndrome, such as hypertension, dyslipidaemia and insulin resistance. The strong association between psoriasis and obesity potentially makes psoriasis an important healthcare issue that requires an update in its standard of care [20]. In this study, 7 cases with severe PASI were females without family history of psoriasis, 6 of them were obese. This study reported that the risk of developing psoriasis was directly related to increase in BMI more than $30(r=$ $0.7, P=0.007)$. So, the obesity will play an another factor plus the genetic factor in developing psoriasis.

The pathogenesis of psoriasis is not clear till now. This study provided a new evidence about the role of
IL-12 in the pathogenesis of psoriatic arthritis. Moreover, to our knowledge, for the first time these findings suggested that psoriatic arthritis may have a separate pathogenic pathway as IL-12 significantly increased in psoriatic arthritis. While psoriasin, kobneriasin and IL23 could play a role in the pathogenesis of skin psoriasis. However, other studies are required to further investigate the differences in these two possible pathological pathways for psoriasis. In conclusion, psoriasin is the first biomarker confirm the link between obesity and psoriasis. Psoriasin and IL-23 will be important new therapeutic targets for patients with skin psoriasis. Whereas, targeting of IL-12 or its receptor is a potential therapeutic approach for psoriatic arthritis. The obesity of psoriatic patients may reflect a common pathophysiology and not simply a sedentary behavior derived from the disfiguring cutaneous condition.

\section{Acknowledgements}

The authors declared that this research granted from Scientific Research Deanship of Qassim University, Ministry of Higher Education, Kingdom of Saudi Arabia grant \# SRD-2011-623.

\section{References}

[1] M.I. Fatani, M.H. Abdulghani, K.A. Al-Afif. Psoriasis in the eastern Saudi Arabia. Saudi Med J 23 (2002) 213-217.

[2] R. Wolf, T. Ruzicka, S.H. Yuspa. Novel S100A7 (psoriasin)/S100A15 (koebnerisin) subfamily: Highly homologous but distinct in regulation and function. Amino Acids 41 (2011) 789-796.

[3] S. Zwicker, D. Bureik, T. Ruzicka, R. Wolf. [Friend or Foe - Psoriasin and Koebnerisin: Multifunctional defence molecules in skin differentiation, tumorigenesis and inflammation]. Dtsch Med Wochenschr 137 (2012) 491-494.

[4] Z. Hegyi, S. Zwicker, D. Bureik, M. Peric, S. Koglin, A. Batycka-Baran, J.C. Prinz, T. Ruzicka, J. Schauber, R. Wolf. Vitamin D Analog Calcipotriol Suppresses the Th17 Cytokine-Induced Proinflammatory S100 "Alarmins" Psoriasin (S100A7) and Koebnerisin (S100A15) in Psoriasis. J Invest Dermatol 486 (2012). [Epub ahead of print].

[5] B. Oppmann, R. Lesley, B. Blom, J.C. Timans, Y. Xu, B. Hunte, F. Vega, N. Yu, J. Wang, K. Singh, F. Zonin, E. Vaisberg, T. Churakova, M. Liu, D. Gorman, J. Wagner, S. Zurawski, Y. Liu, J.S. Abrams, K.W. Moore, D. Rennick, R. de Waal-Malefyt, C. Hannum, J.F. Bazan, R.A. Kastelein. Novel p19 protein engages IL-12p40 to form a cytokine, IL-23, with biological activities similar as well as distinct from IL-12. Immunity 13 (2000) 715-25.

[6] J.M. Benson, D. Peritt, B.J. Scallon, G.A. Heavner, D.J. Shealy, J.M. Giles-Komar, M.A. Mascelli. Discovery and mechanism of ustekinumab: A human monoclonal antibody targeting interleukin-12 and interleukin-23 for treatment of immune-mediated disorders. MAbs 3 (2011) 535-45. 
[7] A. Saalbach, K. Vester, K. Rall, J. Tremel, U. Anderegg, A.G. Beck-Sickinger, M. Blüher, J.C. Simon. Vaspin-a link of obesity and psoriasis? Exp Dermatol 21 (2012) 309-12.

[8] W. Li, J. Han, A.A. Qureshi. Obesity and risk of incident psoriatic arthritis in US women. Ann Rheum Dis (2012). [Epub ahead of print].

[9] C. Ryan, A. Menter. Psoriasis and cardiovascular disorders. $G$ Ital Dermatol Venereol 147 (2012) 179-87.

[10] J. Orgaz-Molina, A. Buendía-Eisman, M.A. Arrabal-Polo, J.C. Ruiz, S. Arias-Santiago. Deficiency of serum concentration of 25-hydroxyvitamin D in psoriatic patients: A case-control study. J Am Acad Dermatol (2012).

[11] T. Fredriksson, U. Pettersson. Severe psoriasis - oral therapy with a new retinoid. Dermatologica 157 (1978) 238-244.

[12] W. Taylor, D. Gladman, P. Helliwell, A. Marchesoni, P. Mease, H. Mielants. CASPAR Study Group: Classification criteria for psoriatic arthritis: development of new criteria from a large international study. Arthritis Rheum 54 (2006) 2665-73.

[13] R. Wolf, T. Ruzicka, S.H. Yuspa. Novel S100A7 (psoriasin)/S100A15 (koebnerisin) subfamily: Highly homologous but distinct in regulation and function. Amino Acids 41 (2011) 789-96.

[14] Garcia-Rodriguez S, Arias-Santiago S, Perandrés-López R, Castellote L, Zumaquero E, Navarro P, Buendía-Eisman A, Ruiz JC, Orgaz-Molina J, Sancho J, Zubiaur M. Increased gene expression of Toll-like receptor 4 on peripheral blood mononuclear cells in patients with psoriasis. J Eur Acad Dermatol Venereol. doi: 10.1111/j.1468-3083.2011.04372.x.
[15] T. Gambichler, F.G. Bechara, N. Scola, S. Rotterdam, P. Altmeyer, M. Skrygan. Serum levels of antimicrobial peptides and proteins do not correlate with psoriasis severity and are increased after treatment with fumaric acid esters. Arch Dermatol Res 304 (2012) 471-4.

[16] C. Tang, S. Chen, H. Qian, W. Huang. Interleukin-23: As a drug target for autoimmune inflammatory diseases. Immunology 135 (2012) 112-24.

[17] H. El Hadidi, B. Grace,T. Gheita, O. Shaker. Involvement of IL23 in psoriasis and psoriatic arthritis. patients; possible role in pathogenesis. J Egypt wom Dermatol Soc 5 (2008) 70-75.

[18] Y. Tokano, S. Morimoto, H. Kaneko, H. Amano, K. Nozawa, Y. Takasaki, H. Hashimoto. Levels of IL-12 in the sera of patients with systemic lupus erythematosus (SLE) relation to Th1 and Th2 derived cytokines. Clin Exp Immunol 116 (1999) 169-173.

[19] S. Arias-Santiago, J. Orgaz-Molina, L.Castellote-Caballero, M.Á. Arrabal-Polo, S. García-Rodriguez, R. Perandrés-López, J.C. Ruiz, R. Naranjo-Sintes, M. Zubiaur, J. Sancho, A. Buendía-Eisman. Atheroma plaque, metabolic syndrome and inflammation in patients with psoriasis. Eur J Dermatol 22 (2012) 337-44

[20] W. Sterry, B.E. Strober, A. Menter. Obesity in psoriasis: the metabolic, clinical and therapeutic implications. Report of an interdisciplinary conference and Review, Meeting report. The International Psoriasis Council. DOI 10.1111/j.13652133.2007.08068.x. 


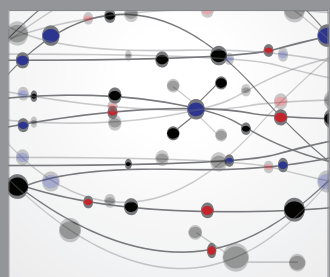

The Scientific World Journal
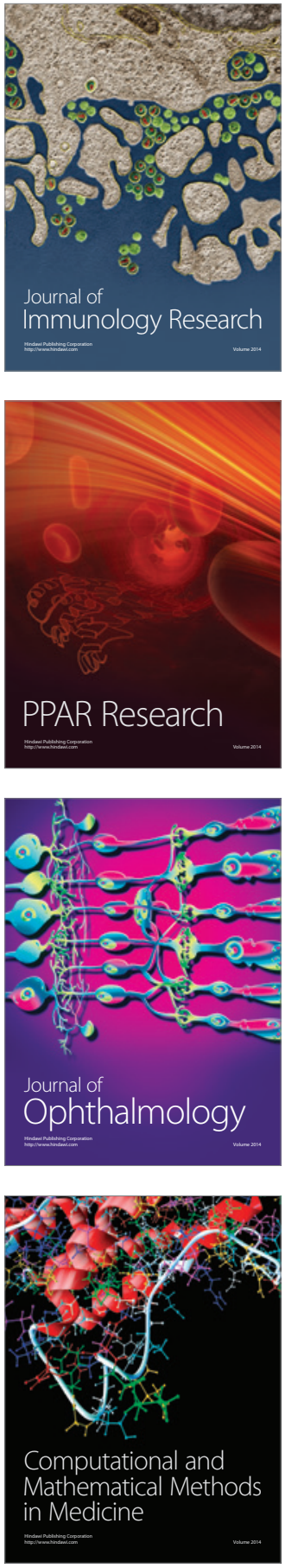

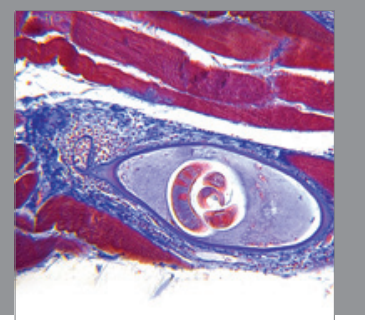

Gastroenterology

Research and Practice
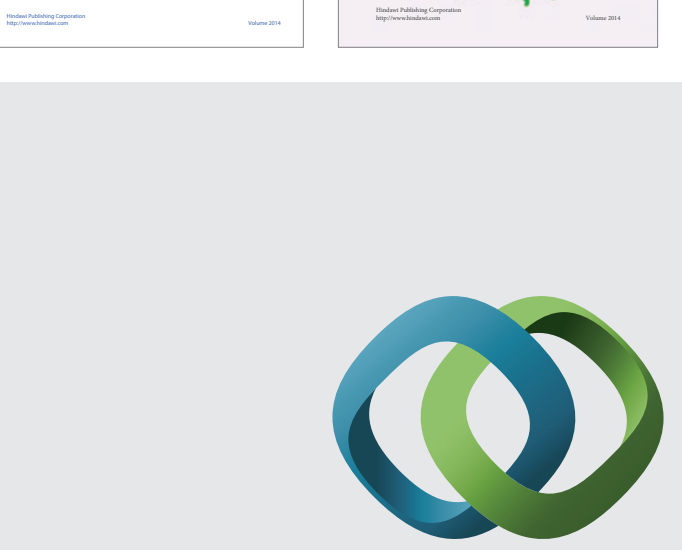

\section{Hindawi}

Submit your manuscripts at

http://www.hindawi.com
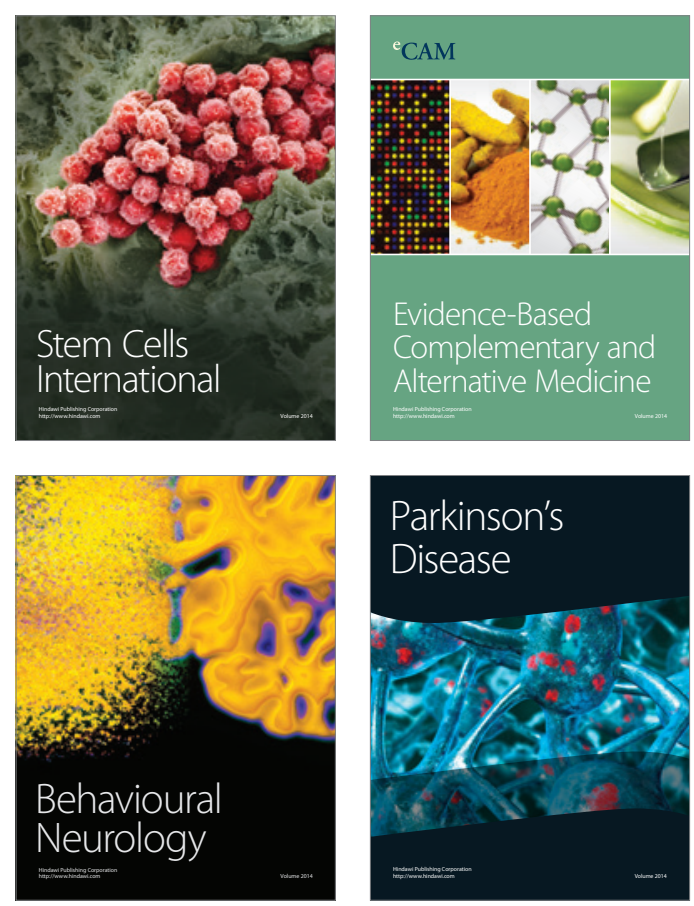

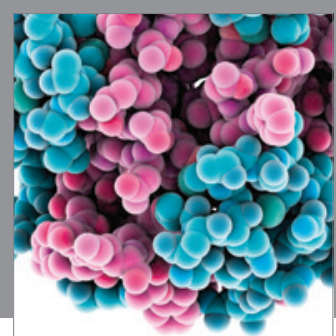

Journal of
Diabetes Research

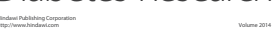

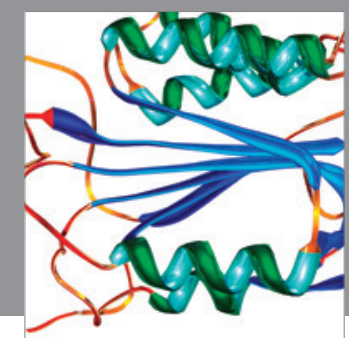

Disease Markers
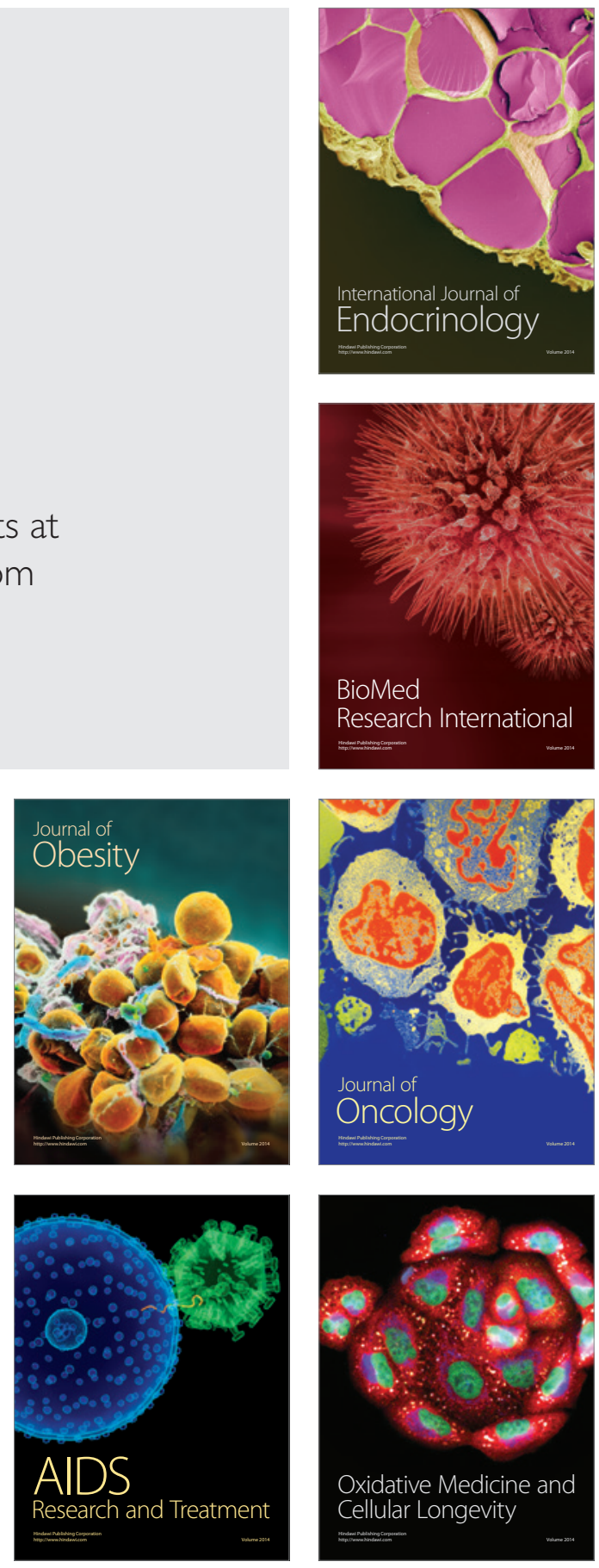